
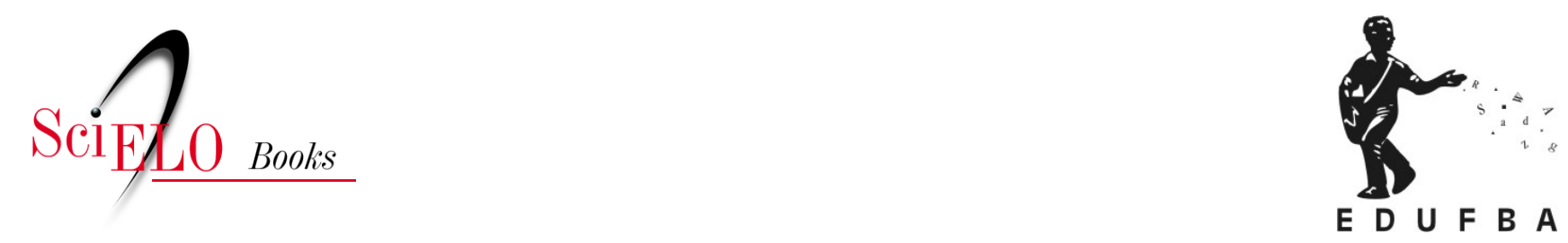

\title{
Semiologia nutricional
}

\author{
Lílian Ramos Sampaio \\ Maria da Conceição Monteiro da Silva \\ Tatiane Melo de Oliveira \\ Venusca Rocha Leite
}

SAMPAIO, L.R., SILVA, M.C.M, OLIVEIRA, T.M., and LEITE, V.R. Semiologia nutricional. In: SAMPAIO, L.R., org. Avaliação nutricional [online]. Salvador: EDUFBA, 2012, pp. 23-47. Sala de aula collection. ISBN: 978-85-232-1874-4. https://doi.org/10.7476/9788523218744.0004.

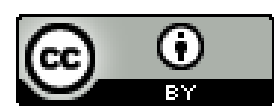

All the contents of this work, except where otherwise noted, is licensed under a Creative Commons Attribution $\underline{4.0 \text { International license. }}$

Todo o conteúdo deste trabalho, exceto quando houver ressalva, é publicado sob a licença Creative Commons Atribição 4.0.

Todo el contenido de esta obra, excepto donde se indique lo contrario, está bajo licencia de la licencia Creative Commons Reconocimento 4.0. 


\title{
Semiologia nutricional
}

\author{
Lílian Ramos Sampaio \\ Maria da Conceição Monteiro da Silva \\ Tatiane Melo de Oliveira \\ Venusca Rocha Leite
}

O termo semiologia, criado a partir do grego sèmeion (sinal) e logos (estudo, ciência), designa a ciência dos sinais, isto é, a ciência que estuda a organização dos sistemas significantes.

$\mathrm{Na}$ área da saúde, a semiologia compreende o estudo dos sinais e sintomas do indivíduo, no qual os sinais representam as manifestações clínicas de uma doença observadas pelo examinador por meio da inspeção, palpação ou ausculta. Os sintomas são sensações subjetivas, sentidas pelo indivíduo e não visualizada pelo examinador. E, para avaliação dessas alterações e/ou manifestações semiológicas, no que se refere aos problemas nutricionais, o nutricionista dispõe da anamnese nutricional para a identificação dos sintomas clínicos nutricionais e do exame físico na avaliação dos sinais clínicos nutricionais.

O exame clínico nutricional consiste em avaliar as alterações orgânicas expressas nos tecidos externos 
do indivíduo, ou mesmo a evolução de patologias já existentes no organismo. Estas situações possivelmente podem associar-se à inadequação alimentar, seja por deficiência ou excesso na ingestão. Assim, por meio da semiologia nutricional, busca-se determinar as condições nutricionais do paciente, identificar os sinais e sintomas de carência ou excesso de nutrientes e correlacioná-los com os hábitos alimentares. É um indicador subjetivo, uma vez que sua avaliação não resulta em um valor, e sim nas impressões individuais do avaliador e do avaliado.

É importante lembrar que para o sinal clínico ser considerado consequência de problemas nutricionais ele deve ser primordialmente bilateral. Sendo assim, a avaliação é realizada minuciosamente, sendo priorizados, no momento do exame, aqueles sinais referentes aos problemas de maior prevalência nas diferentes faixas etárias e considerando as informações obtidas a partir da avaliação da anamnese e do consumo alimentar.

Apesar da facilidade de aplicação desse método, a semiologia nutricional apresenta como principais limitações o fato de que as manifestações clínicas são evidenciadas apenas nos estados mais avançados de excesso e/ou carência nutricional, e para adequada identificação é necessário treinamento para melhorar a habilidade no reconhecimento dos sinais clínicos nutricionais.

\section{Anamnese Nutricional}

A palavra anamnese vem do grego anmnesis e significa recordar. $\mathrm{Na}$ prática clínica, significa a rememoração dos eventos relacionados à saúde e à identificação dos sintomas e sinais atuais, com o intuito principal de possibilitar entender, com a maior precisão possível, a história dos motivos que traz o paciente à 
consulta. Dessa forma, a anamnese ou história clínica é de grande relevância para se reconhecer e entender as três dimensões do diagnóstico: o paciente, a moléstia e as circunstâncias associadas. Além disso, a anamnese é indispensável para o alcance de uma relação entre paciente e profissional adequada. A importância deste tipo de relacionamento é evidente, já que dele dependerá, em sua maior parte, o grau de confiança que o paciente irá depositar nesse profissional, a qualidade das informações que serão transmitidas ou mesmo a colaboração que o paciente oferecerá em relação à adesão da conduta terapêutica. Na nutrição, o sucesso da conduta é, em maior parte, dependente de mudanças nos hábitos alimentares, estes que, na maioria das vezes, representam um desafio, sendo imprescindível uma relação harmônica do binômio paciente-nutricionista.

$\mathrm{Na}$ avaliação nutricional, a história clínica é direcionada para identificação da situação nutricional e de fatores de determinação associados. O paciente deve então ser interrogado sobre fatores que interferem direta ou indiretamente no estado nutricional: perda ou ganho ponderal recente; sinais de doenças gastrointestinais, como náuseas, vômitos, diarreia; uso de medicamentos que interferem na absorção e na utilização dos nutrientes; presença de fatores limitantes na ingestão adequada, como anorexia, lesões bucais, dificuldades de mastigação; presença de doenças crônicas ou intervenções cirúrgicas e etilismo e tabagismo, além de fatores psíquicos que possam interferir na ingestão alimentar.

Apesar de importante, a história clínica nutricional não deve ser usada isoladamente, uma vez que a capacidade desse método depende de variáveis como: condição clínica e tipo de informante (em geral, o paciente ou acompanhante) e de entrevistador (no caso, o nutricionista) - situações estas que, quando não se apresentam de maneira positiva, podem comprometer a eficácia da 
anamnese. Na maioria das vezes, as dificuldades existentes estão na deficiência de comunicação entre o paciente e o profissional de saúde. Sendo assim, este último deve estar preparado e saber como irá atuar nas diversas situações listadas no quadro 1.

- Deficiência na fonação ou audição

- Diferenças de linguagem

- Depressão do estado de consciência

- Distúrbios mentais

- Crianças - Falta de objetividade - Incoerência

- Deficiência de memória e observação

- Concepções errôneas sobre a moléstia

- Falta de confiança na nutrição

- Inibição e/ou distração causadas pela presença de outras pessoas

Quadro 1 - Limitações da anamnese decorrentes do paciente Fonte: Adaptado de López e Medeiros (2001).

Além da anamnese geral, na avaliação nutricional temos a anamnese alimentar. Esta representa o ponto de partida para a avaliação da ingestão alimentar. Feita com base nos inquéritos alimentares, busca-se fazer com que o paciente relate como é o seu padrão alimentar e os fatores relacionados.

\section{Exame Físico}

A realização do exame físico, tanto geral como específico, é importante, pois irá complementar a história clínica, alimentar e 
nutricional e proporcionar elementos capazes de apoiar hipóteses sobre o diagnóstico nutricional. O exame físico geral pode avaliar uma série de dados do paciente, incluindo os antropométricos e sinais clínicos. O exame físico engloba observações dos diversos tecidos de proliferação rápida, os quais refletem precocemente problemas nutricionais, quando comparados a outros tecidos, sistemas corporais (cardiovascular, respiratório, neurológico e gastrointestinal) dos tecidos adiposo e muscular e da condição hídrica do paciente, buscando sempre investigar a presença de alterações específicas.

Inicialmente, deve-se registrar a impressão sobre o estado geral do paciente por meio da observação e relato deste. Ânimo, depressão, fraqueza, tipo físico, estado de consciência, discurso e movimentos corporais devem ser investigados.

O exame deve ser realizado de forma sistemática e progressiva, a partir da cabeça até a região plantar. Inicia-se pelo cabelo, seguido dos olhos, narinas, face, boca (lábios, dentes, língua), pescoço (tireóide), tórax (abdome), membros superiores (unhas, região palmar) e inferiores (quadríceps, joelho, tornozelo, região plantar), pele e sistemas (cardiovascular, neurológico, respiratório e gastrointestinal), de acordo com quadro 2.

No caso do adolescente, deve-se examinar também o desenvolvimento das mamas, pelos pubianos e genitália. A fase da pubescência pode ser avaliada através da observação do paciente sobre o seu próprio corpo e utilizando os estágios de Tanner.

Cada parte do corpo deve ser examinada de forma cuidadosa, para que, associada ao relato dos sintomas e de outras informações, seja possível a definição ou suspeita diagnóstica para subsidiar a solicitação dos exames laboratoriais. 


\begin{tabular}{|c|c|c|}
\hline $\begin{array}{l}\text { Região/ } \\
\text { situação exa- } \\
\text { minada }\end{array}$ & $\begin{array}{l}\text { Característica(s) a ser(em) } \\
\text { avaliada(s) }\end{array}$ & $\begin{array}{l}\text { Características em } \\
\text { condições normais }\end{array}$ \\
\hline Cabelo & $\begin{array}{l}\text { Coloração, brilho, quantidade, espessu- } \\
\text { ra, hidratação, ocorrência de alopecia. }\end{array}$ & $\begin{array}{l}\text { Brilhantes, firmes e } \\
\text { difíceis de arrancar, } \\
\text { aparência normal e } \\
\text { espessa, crescimento } \\
\text { normal, macios ao } \\
\text { tato e coloração } \\
\text { adequada. }\end{array}$ \\
\hline Face & $\begin{array}{l}\text { Estado geral, condição físico. Presença } \\
\text { de edema ou depleção (sinal de chave } \\
\text { - exposição do arco zigomático). Apre- } \\
\text { sentação de: palidez, atrofia unilateral } \\
\text { ou bitemporal. Fácies agudo: exausto, } \\
\text { cansado, não consegue manter os olhos } \\
\text { abertos por muito tempo; Fácies crôni- } \\
\text { co: aparência deprimida, triste, pouco } \\
\text { diálogo. }\end{array}$ & $\begin{array}{l}\text { Bom Estado Geral, } \\
\text { sem sinais de deple- } \\
\text { ção ou edema. }\end{array}$ \\
\hline Olhos & $\begin{array}{l}\text { Aspecto, cor das mucosas e membranas, } \\
\text { sinais de excesso de nutrientes - xan- } \\
\text { telasma, arco córneo lipídico, sinais de } \\
\text { deficiência de nutrientes: desnutrição } \\
\text { - olhos escavados, escuros e flacidez ao } \\
\text { redor, hipovitaminoses - xeroftalmia, } \\
\text { nictalopia, etc. }\end{array}$ & $\begin{array}{l}\text { Brilhantes, membra- } \\
\text { nas róseas e úmidas, } \\
\text { sem manchas e boa } \\
\text { adaptação visual no } \\
\text { escuro. }\end{array}$ \\
\hline Lábios & $\begin{array}{l}\text { Coloração da mucosa, presença de } \\
\text { lesões decorrentes de hipovitaminoses. }\end{array}$ & $\begin{array}{l}\text { Lábios macios e sem } \\
\text { inflamações. }\end{array}$ \\
\hline Língua & $\begin{array}{l}\text { Coloração, integridade papilar, edema, } \\
\text { espessamento. }\end{array}$ & $\begin{array}{l}\text { Língua vermelha, } \\
\text { sem edema, com } \\
\text { superfície normal e } \\
\text { paladar preservado. }\end{array}$ \\
\hline Gengivas & Edema, porosidade e sangramento & $\begin{array}{l}\text { Ausência de sangra- } \\
\text { mentos e edema. }\end{array}$ \\
\hline Peças dentárias & $\begin{array}{l}\text { Presença de cáries, ausência de peças } \\
\text { dentárias, uso de prótese (bem adaptada } \\
\text { ou não), alterações em função de exces- } \\
\text { so ou escassez de nutrientes. }\end{array}$ & $\begin{array}{l}\text { Arcada dentária ín- } \\
\text { tegra, sem ausência } \\
\text { de peças dentárias } \\
\text { ou uso de prótese } \\
\text { bem adaptada - não } \\
\text { ocasionar compro- } \\
\text { metimento da mas- } \\
\text { tigação. }\end{array}$ \\
\hline
\end{tabular}




\begin{tabular}{|c|c|c|}
\hline $\begin{array}{l}\text { Região/ } \\
\text { situação exa- } \\
\text { minada }\end{array}$ & $\begin{array}{l}\text { Característica(s) a ser(em) } \\
\text { avaliada(s) }\end{array}$ & $\begin{array}{l}\text { Características em } \\
\text { condições normais }\end{array}$ \\
\hline Pele & $\begin{array}{l}\text { Cor, pigmentação, integridade, turgor, } \\
\text { presença de edema, brilho e temperatu- } \\
\text { ra, manifestações decorrentes de defici- } \\
\text { ência ou excesso de nutrientes. }\end{array}$ & $\begin{array}{l}\text { Cor uniforme, lisa, } \\
\text { aparência saudável, } \\
\text { turgor preservados } \\
\text { ou compatíveis com } \\
\text { a idade (no caso de } \\
\text { idosos). }\end{array}$ \\
\hline Unhas & $\begin{array}{l}\text { Forma, ângulo, coloração, contorno, } \\
\text { rigidez e presença de micoses. }\end{array}$ & $\begin{array}{l}\text { Uniformes, arre- } \\
\text { dondadas, lisas e } \\
\text { firmes. }\end{array}$ \\
\hline Abdôme & $\begin{array}{l}\text { Quanto à rigidez: flácido ou tenso; } \\
\text { quanto ao volume: distendido, plano, } \\
\text { globoso ou escavado; quanto à presença } \\
\text { de gases: poucos gazes (normal), maciez } \\
\text { (quando há tumor) ou timpânico. }\end{array}$ & $\begin{array}{l}\text { Ausência das altera- } \\
\text { ções referidas. }\end{array}$ \\
\hline $\begin{array}{l}\text { Tecido } \\
\text { subcultâneo }\end{array}$ & $\begin{array}{l}\text { Excesso de tecido adiposo, ou déficit de } \\
\text { tecido subcutâneo - flacidez; presença } \\
\text { de edema }\end{array}$ & $\begin{array}{l}\text { Ausência das altera- } \\
\text { ções referidas. }\end{array}$ \\
\hline $\begin{array}{l}\text { Tecido Muscular } \\
\text { esquelético }\end{array}$ & Retração ou atrofia & $\begin{array}{l}\text { Ausência das altera- } \\
\text { ções referidas. }\end{array}$ \\
\hline Sistema nervoso & $\begin{array}{l}\text { Perdas do controle na contração ou } \\
\text { parestesias }\end{array}$ & $\begin{array}{l}\text { Ausência das altera- } \\
\text { ções referidas. }\end{array}$ \\
\hline $\begin{array}{l}\text { Condição hí- } \\
\text { drica }\end{array}$ & Desidratação ou edema* & $\begin{array}{l}\text { Ausência das altera- } \\
\text { ções referidas. }\end{array}$ \\
\hline
\end{tabular}

Quadro 2 - Região do corpo a ser examinada e características específicas a serem avaliadas

$\star$ O edema de causa nutricional deve ser: frio, mole, indolor, geralmente não forma cacifo e é bilateral

Fonte: Adaptado de Bevilacqua (1997); Martins (2008).

Antes de dar início à realização do exame, deve-se ter atenção aos critérios de preparação e organização:

- $\quad$ O profissional deve ter cuidado com a contaminação pessoal e ao paciente: deve-se ter uma higiene criteriosa, tanto das mãos do avaliador, quanto dos equipamentos que serão utilizados. Lembrando que essa higiene deve sempre 
acontecer antes do início da avaliação e entre um paciente e outro. Caso seja necessário, o profissional deve fazer uso de EPI's (equipamentos de proteção): luvas, máscaras, jaleco, etc. Isso irá garantir uma maior segurança, tanto para o avaliador como para o paciente;

- $\quad$ O paciente deve ser preparado previamente para a realização do exame; o avaliador deve explicar todos os procedimentos a serem realizados, os equipamentos utilizados, as posições necessárias e dar uma prévia do tempo de duração. Assim, o paciente melhor informado poderá colaborar com a avaliação e evitar situações constrangedoras;

- $\quad$ A vestimenta deve ser adequada, tanto para o profissional como para o paciente, procurando sempre manter o corpo do avaliado o mais coberto possível, deixando descobertas somente as áreas a serem avaliadas;

- Realizar os procedimentos sempre em locais adequados: o paciente deve se sentir à vontade; é importante a privacidade, um ambiente silencioso, suficientemente iluminado e com temperatura confortável;

- $\quad$ Para avaliação do abdome, o paciente deve estar com a bexiga vazia. Os procedimentos como aferição do peso devem ser feitos, de preferência, antes das refeições. Em pacientes hospitalizados, recomenda-se que sejam feitas as aferições de peso com o paciente em jejum;

- $\quad \mathrm{Na}$ aferição da tensão arterial, o paciente não deve estar agitado. A mensuração deve ser realizada quando o paciente estiver tranquilo, preferencialmente do meio para o final da consulta. Deve ser questionada ao paciente a realização de atividade física antes da consulta, bem como a ingestão de medicamentos e de alimentos energéticos e/ou estimu- 
lantes, uma vez que estes elevam a tensão arterial durante um período determinado de tempo, podendo influenciar na aferição da real pressão arterial desse paciente;

- $\quad$ Expressar sempre interesse e respeito pelo problema do paciente, por uma questão humanista e ética e pela contribuição que pode dar para a definição do estabelecimento do diagnóstico;

- Nunca manifestar tristeza ou formular julgamento a respeito do relato da história do paciente. Lembre-se: você não é um juiz, além de que esse comportamento induz à omissão ou exacerbação das respostas.

Existem várias técnicas e procedimentos para a realização do exame físico. Dentre essas, abordaremos aqui as que são direcionadas para a avaliação nutricional:

- Inspeção: para esta técnica, o avaliador irá usar de sua visão, olfato e audição na avaliação do paciente. Por exemplo: verificar a presença de obesidade, caquexia, condição hídrica, integridade da pele, cicatrização de feridas, icterícia, ascite, capacidade funcional, estado mental etc.

- $\quad$ Palpação: trata-se de uma avaliação táctil, onde seu uso tem como objetivo sentir pulsações e vibrações. Através desta técnica, o nutricionista pode avaliar as estruturas corporais como: textura, tamanho, temperatura, consistência e mobilidade. O Turgor, a elasticidade da pele, integridade da derme, tamanho de órgãos, edema periférico, massas abdominais, ascite, perda de peso, entre outros, são exemplos de situações que podem ser detectadas pela técnica de palpação.

- Percussão: consiste na avaliação de "sons", para determinar o contorno, formato e posição destes. Permite avaliar 
também se o órgão está sólido ou se há presença de líquido ou gases. Essa técnica não é sempre necessária no exame clínico nutricional.

- Ausculta: nesta técnica, serão avaliados os sons corpóreos que podem ser ouvidos com ou sem estetoscópio (ex.: sons do coração, dos pulmões - presença de líquidos, intestinais -, ruídos hidroaéreos e dos vasos sanguíneos).

Para algumas carências, este tipo de exame torna-se específico, como no raquitismo (vitamina $\mathrm{D}$ ), bócio endêmico (iodo), mancha de Bitot/xerose da conjuntiva (vitamina A), bem como no excesso de tecido adiposo, em que é possível diagnosticar obesidade etc. Outros sinais e sintomas de alterações específicas encontrados no exame físico são apresentados na tabela 1 .

Apesar de o exame físico ser de baixo custo, de simples execução e importante no reconhecimento da gravidade dos problemas nutricionais, ele necessita de treinamento e do olhar clínico do avaliador. Importante lembrar também a baixa sensibilidade e especificidade dos sinais e sintomas clínicos nutricionais para o diagnóstico nutricional, uma vez que outras situações que não a carência ou excesso de nutrientes podem manifestar-se da mesma forma. A identificação dos desequilíbrios nutricionais por este método é tardia, já que muitas manifestações exteriores só são perceptíveis quando as alterações internas já se encontram graves.

\section{Avaliação muscular subjetiva - AMS}

A AMS visa observar a atrofia de determinados grupamentos musculares, correlacionando-a com a atividade do músculo afetado. Esta é uma técnica facilmente aplicada por observadores treinados, pois não requer o uso de equipamentos e pode ser 
complementada pela história clínica. É de grande utilidade para a avaliação e o acompanhamento clínico da atenção nutricional, por sua capacidade de detectar alterações morfológicas na musculatura responsável pela mastigação, deambulação e vida laborativa. Trata-se, portanto, de um exame físico orientado para quatro grupamentos musculares, envolvidos obrigatoriamente nas atividades rotineiras diárias:

1. Músculo temporal superficial e masseter, relacionados com a mastigação:

a. Atrofia leve: sem exposição do arco zigomático;

b. Atrofia moderada: exposição do arco zigomático;

c. Atrofia grave: quando é possível a visualização do contorno ósseo, envolvendo a órbita, o arco zigomático e o ramo ascendente da mandíbula, sugerindo o desenho de uma "chave".

2. Músculo adutor do polegar, relacionado com a vida laborativa e déficit muscular.

a. Atrofia leve e moderada: depressão em graus variados do relevo muscular;

b. Atrofia grave: possibilidade de visualização de um contorno ósseo do indicador e do polegar, formando uma concha.

3. Músculos interósseos da mão, relacionados com a vida laborativa e déficit muscular.

a. Tróficos: ausência de depleção;

b. Não tróficos: visualização de depleção (perda importante da musculatura). 
4. Músculos da panturrilha, relacionados com a deambulação e déficit muscular.

a. Tróficos: ausência de depleção;

b. Não tróficos: visualização de depleção (perda importante da musculatura).

Os estudos realizados com AMS sugerem complementação deste método com outras técnicas de avaliação nutricional. Sugere-se também a utilização e/ou criação de índices múltiplos, com o objetivo de aumentar a sensibilidade e a especificidade no diagnóstico das alterações nutricionais, uma vez que, até o momento, não existe parâmetro tradicional isolado capaz de estabelecer diagnóstico nutricional fidedigno para o paciente hospitalizado. 


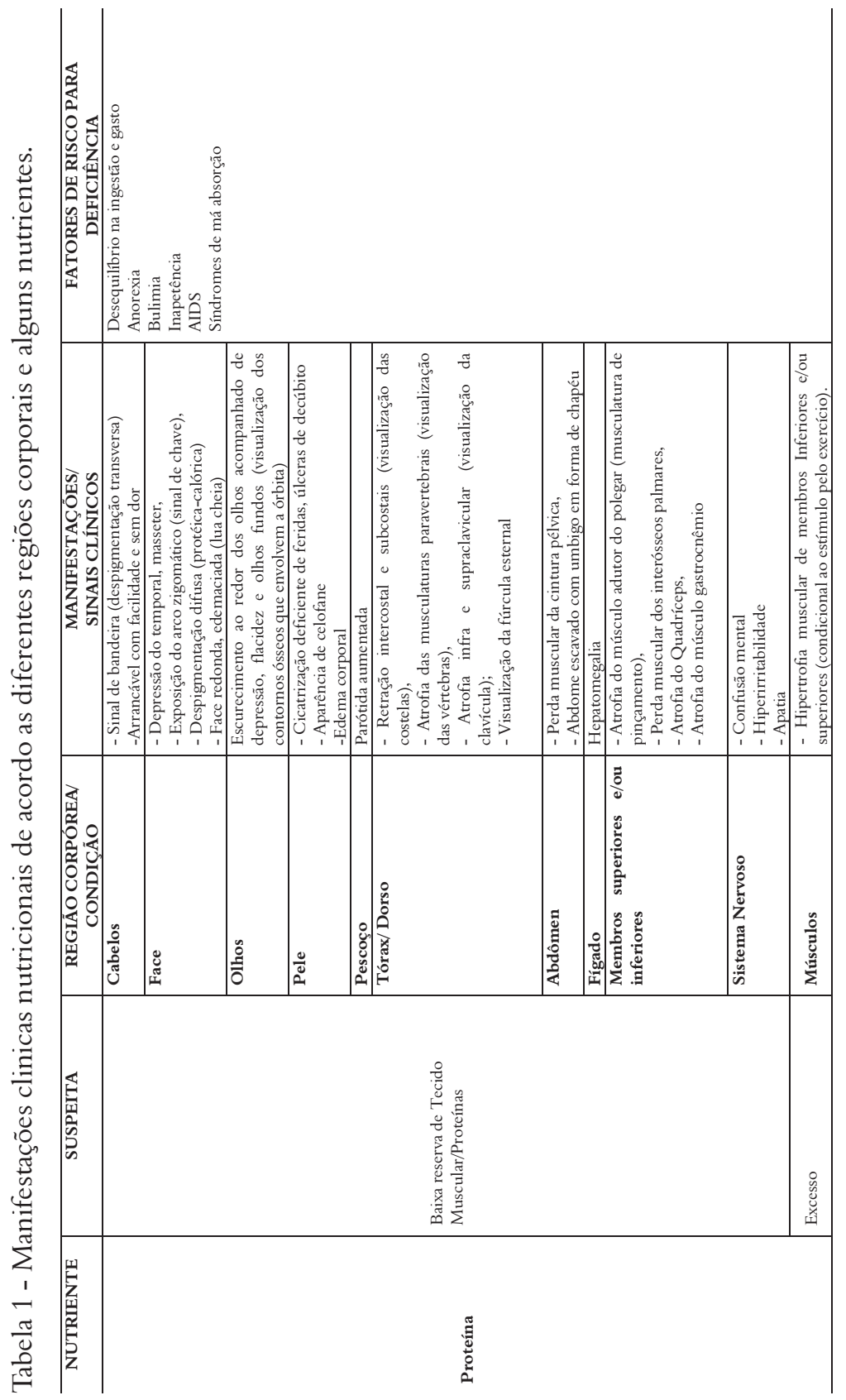

Lílian Sampaio, Maria Silva, Tatiane Oliveira e Venusca Leite 35 


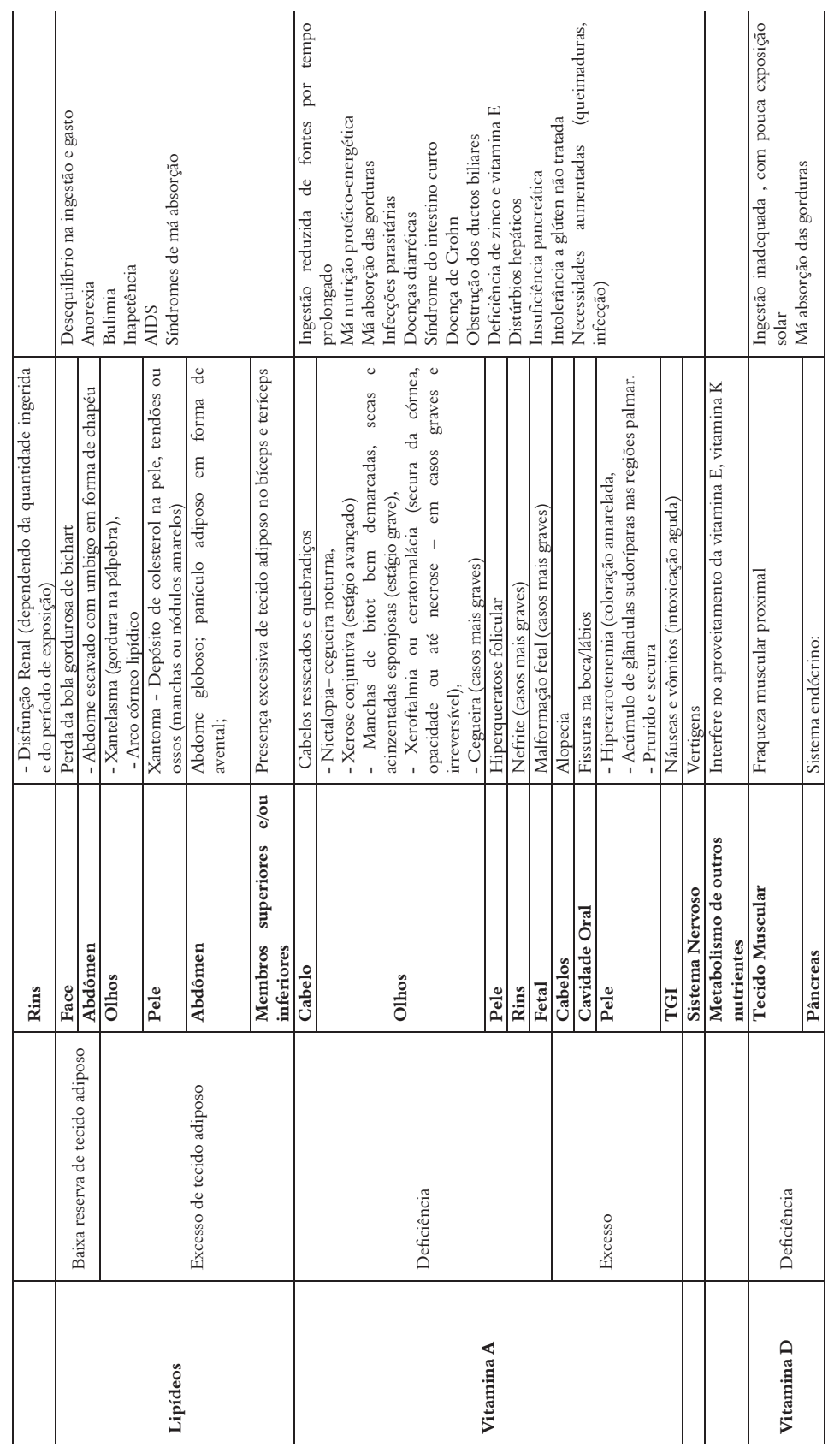

36 Semiologia nutricional 


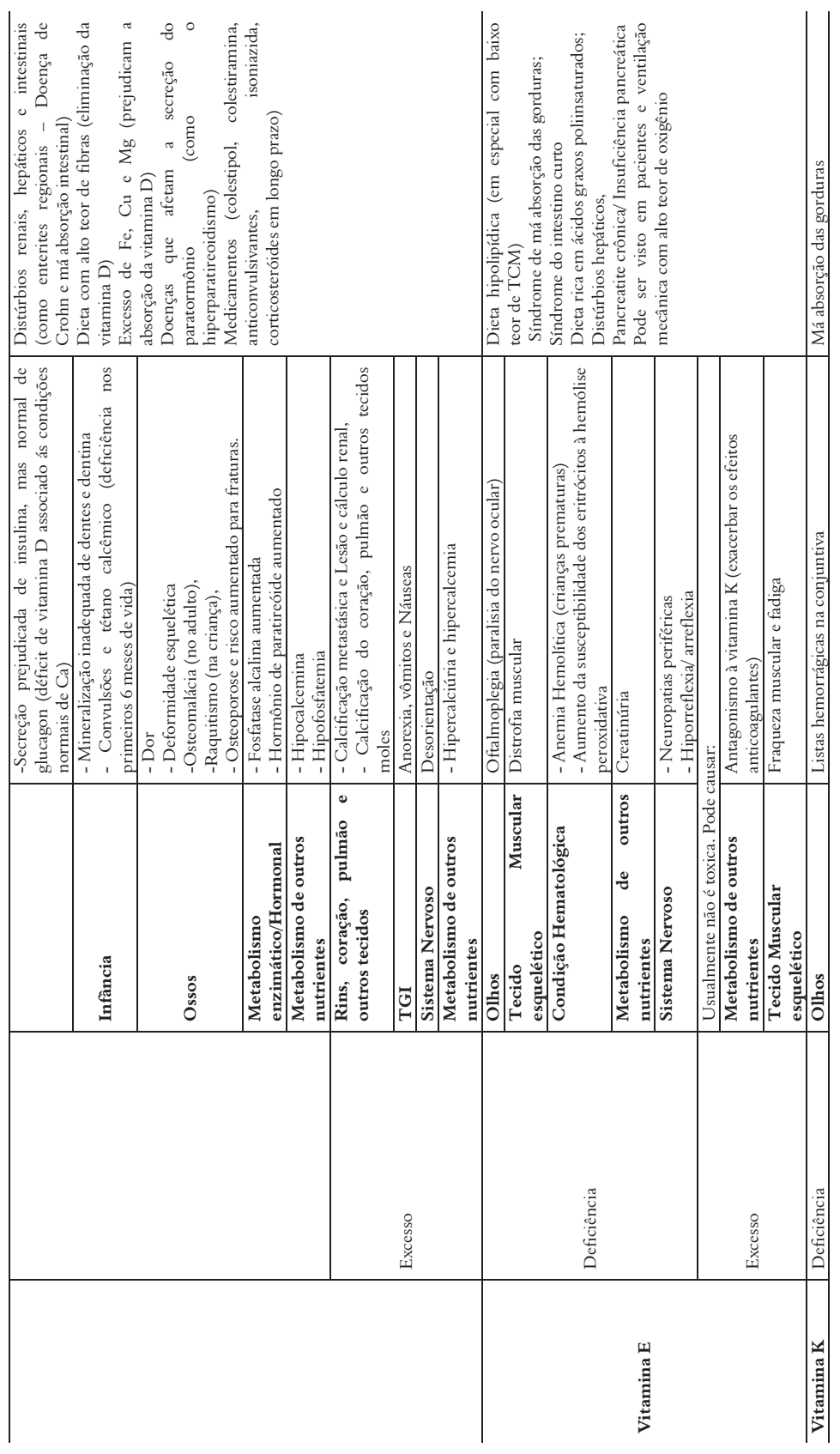




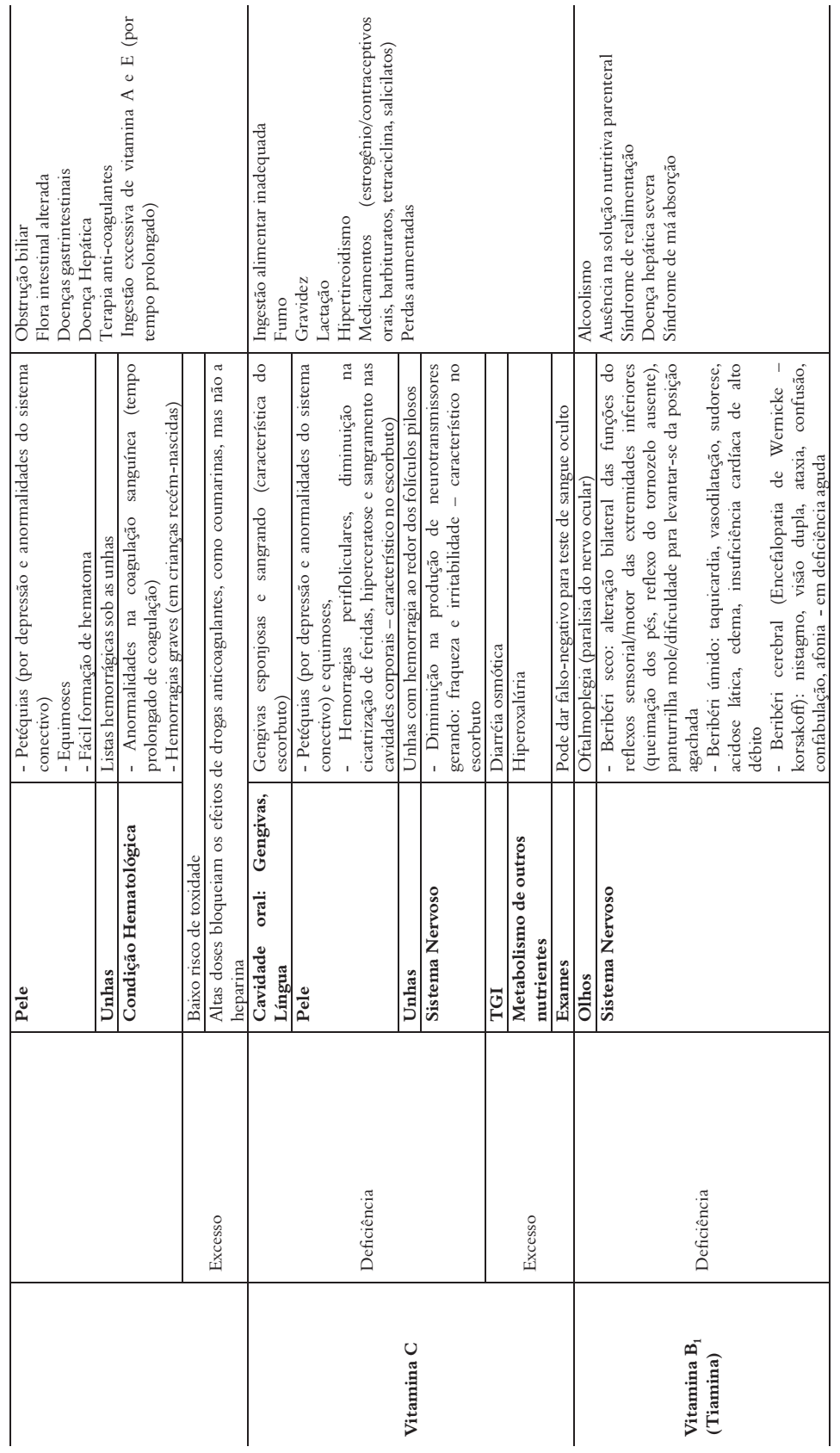

38 Semiologia nutricional 


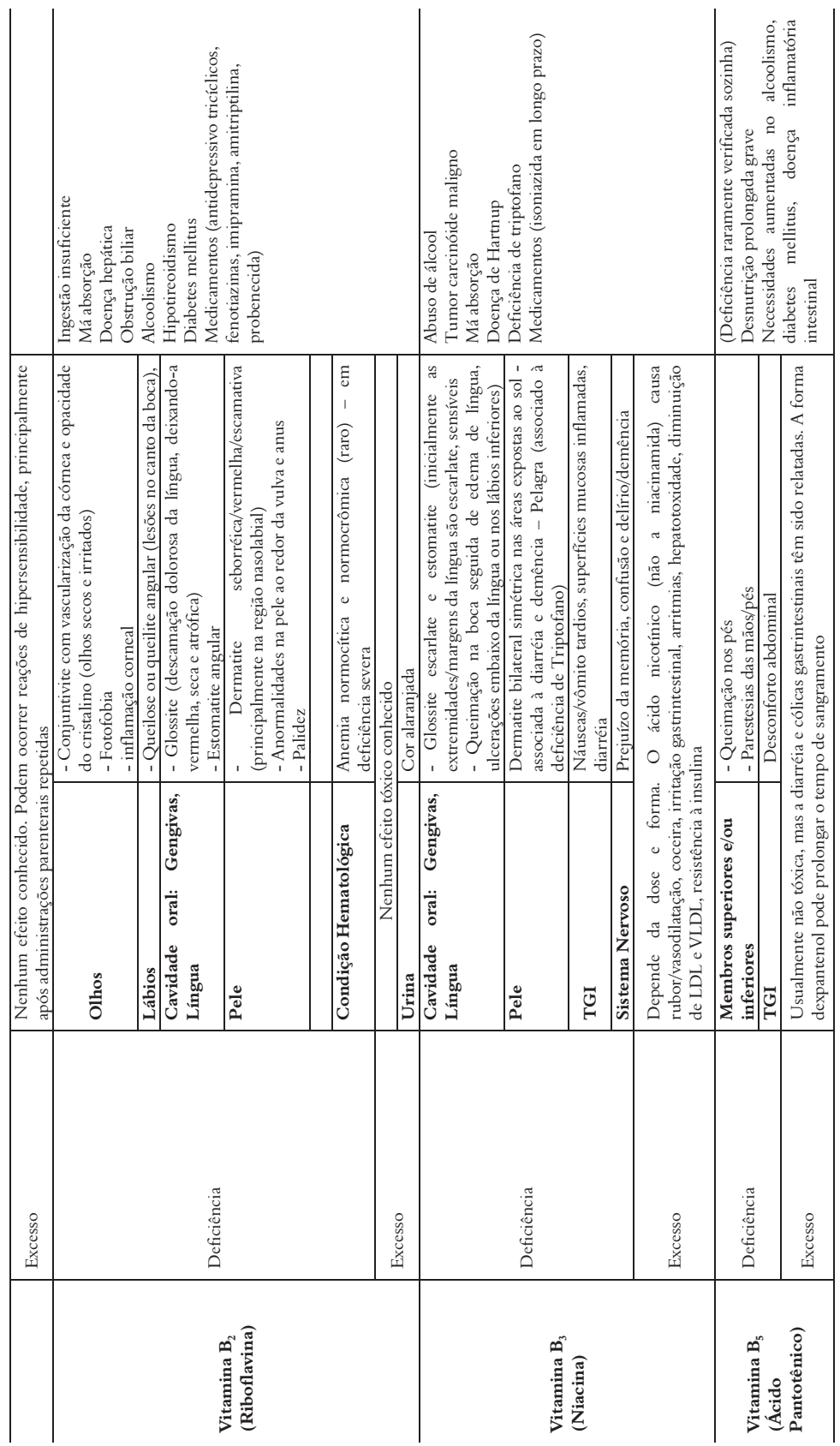




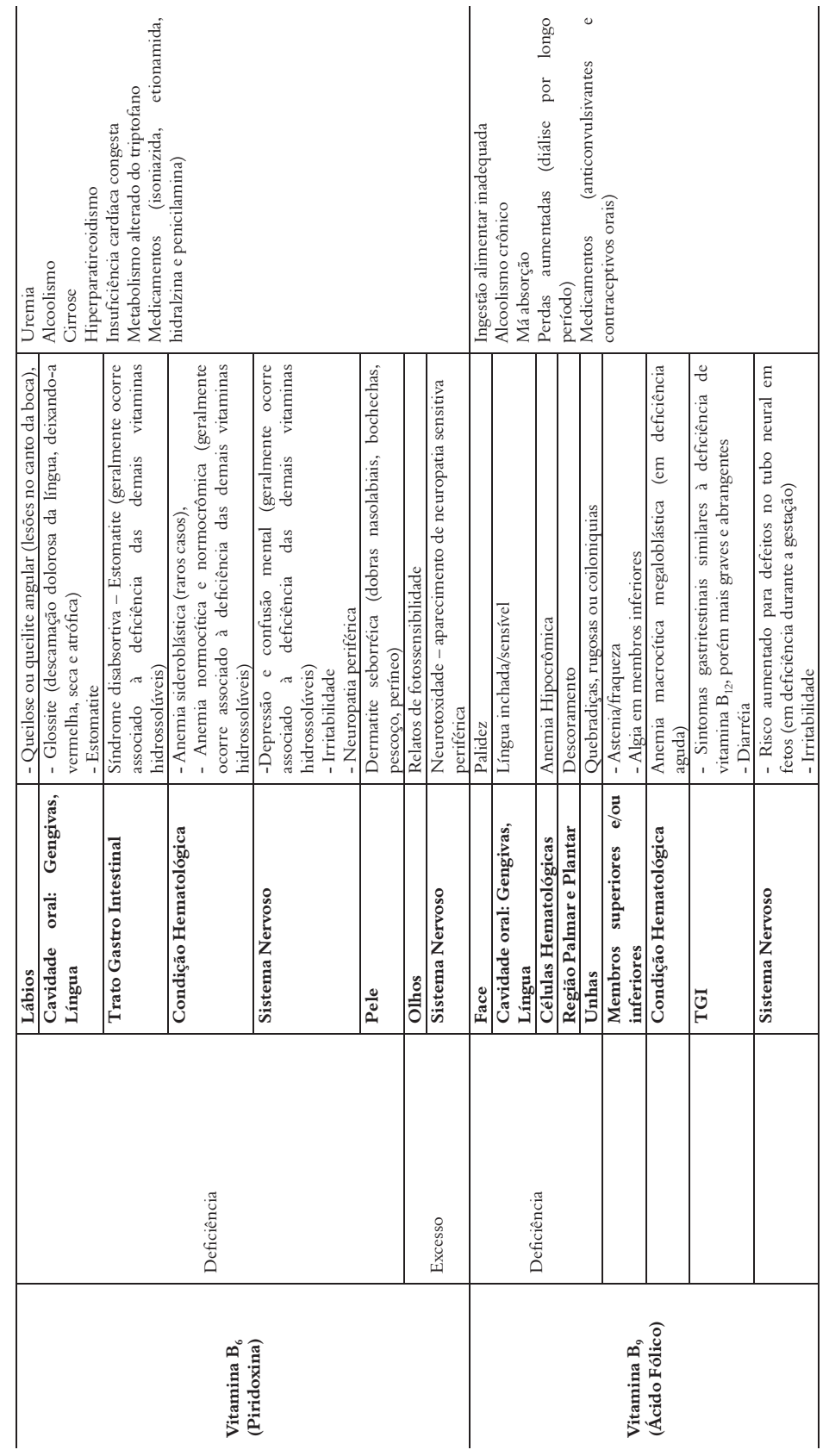

40 Semiologia nutricional 


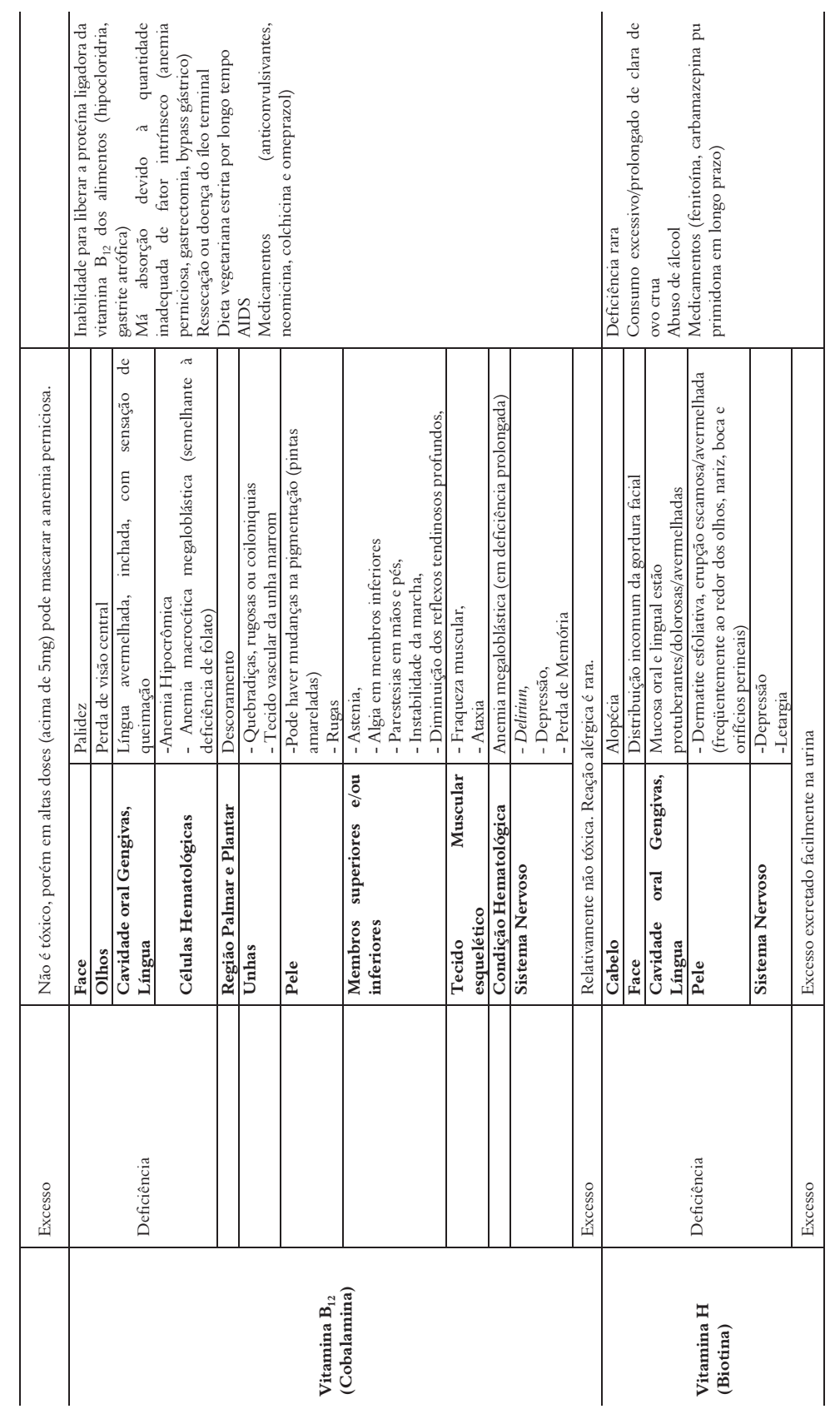




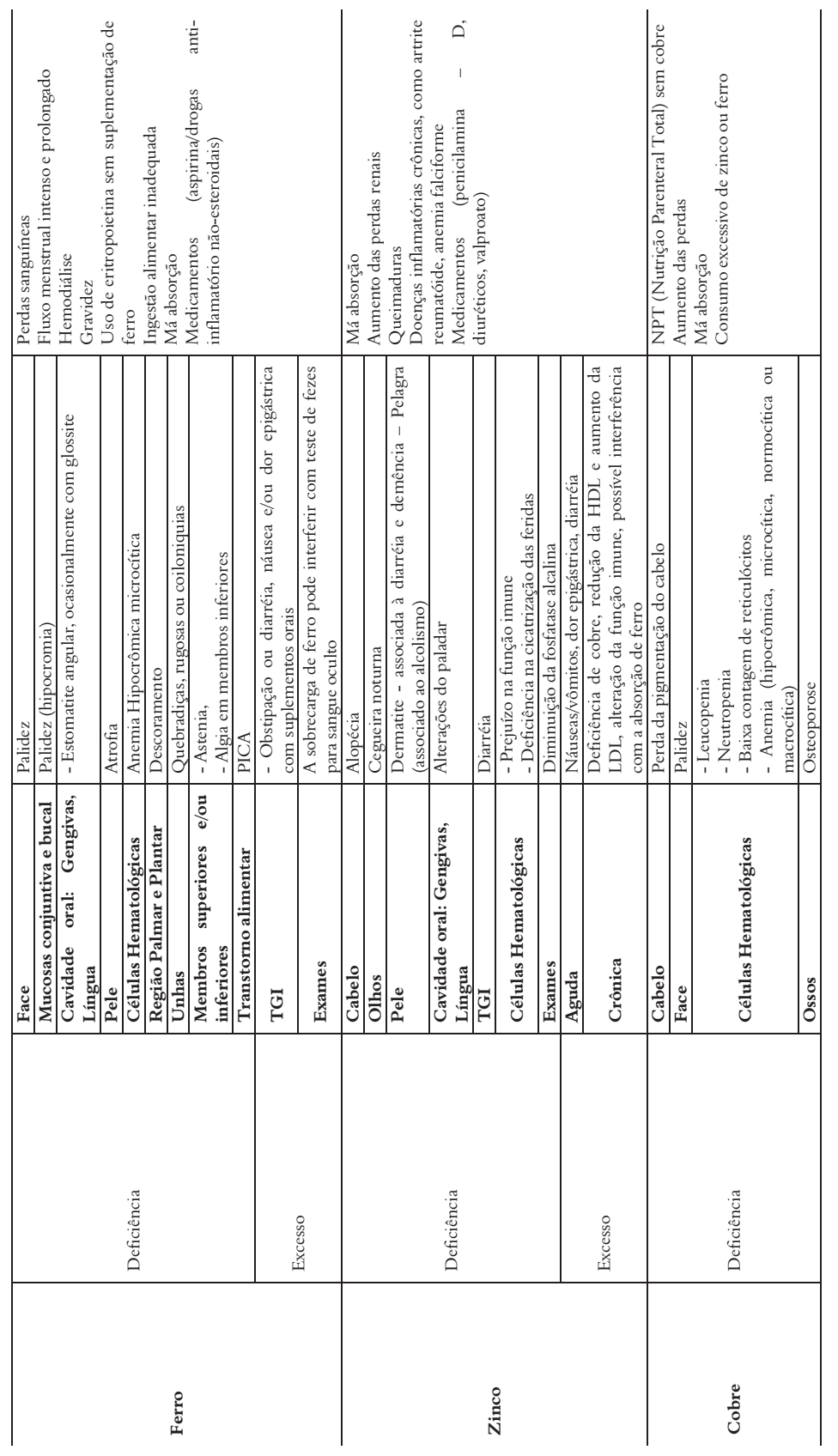

42 Semiologia nutricional 


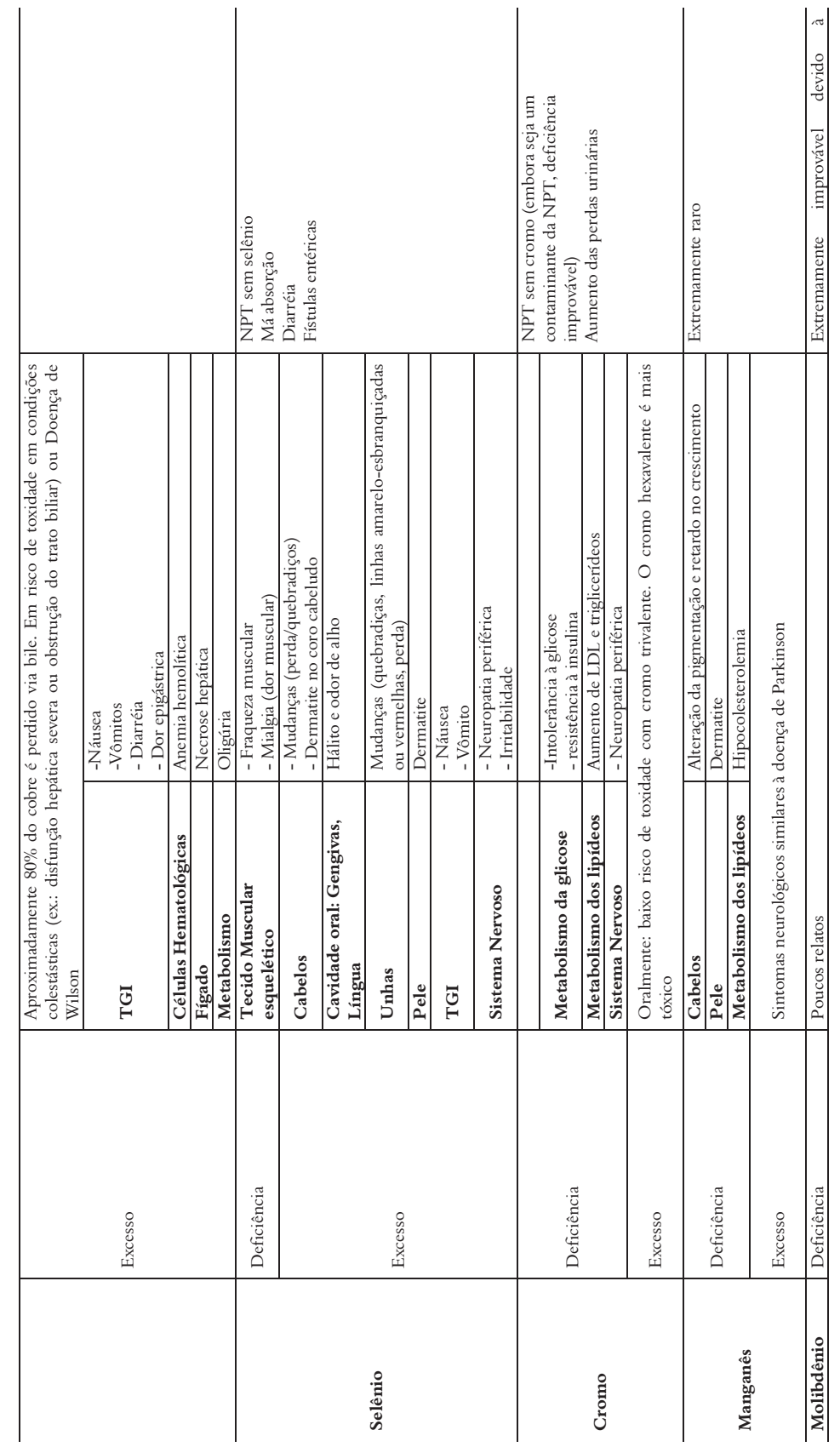




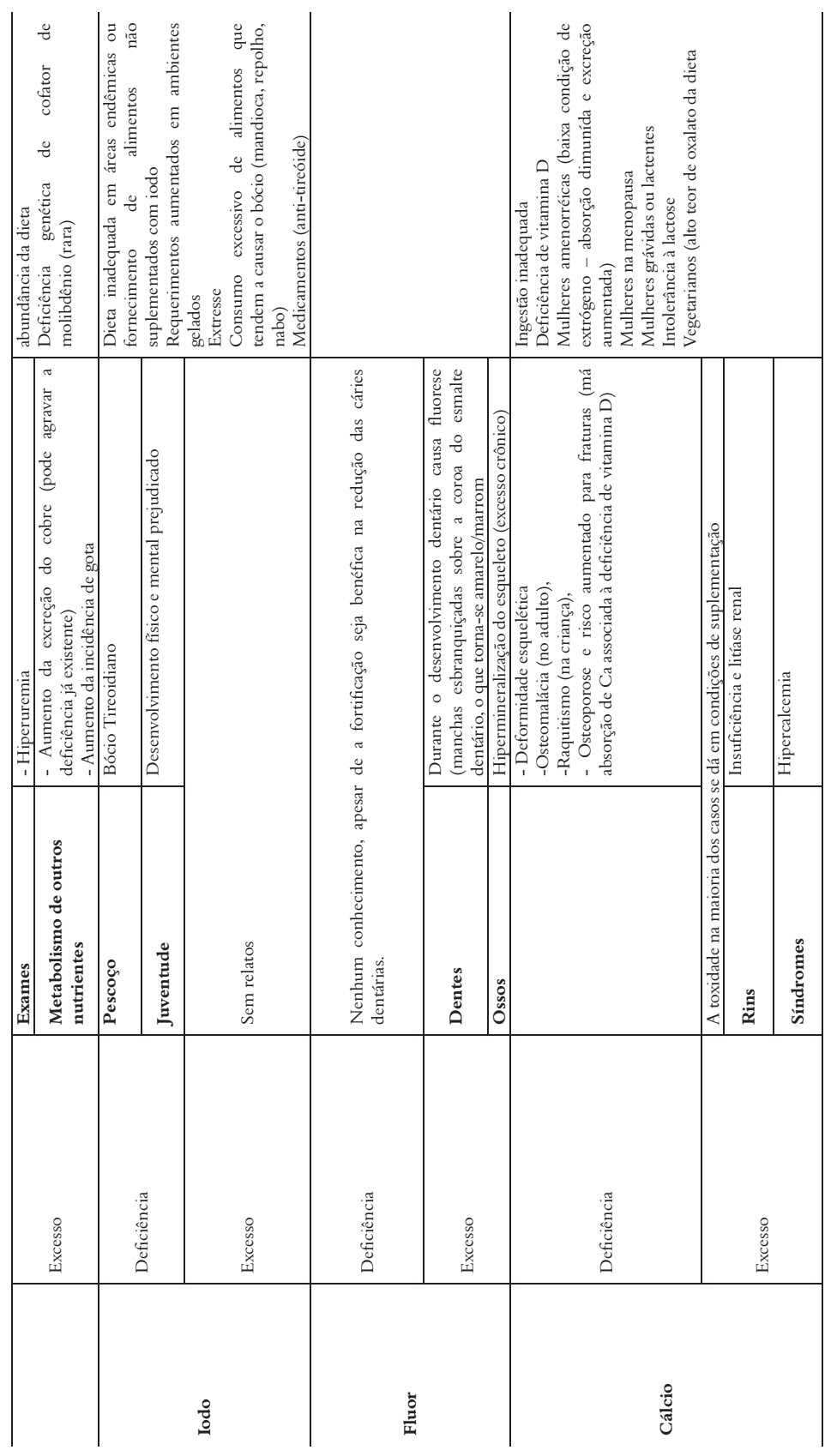

44 Semiologia nutricional 


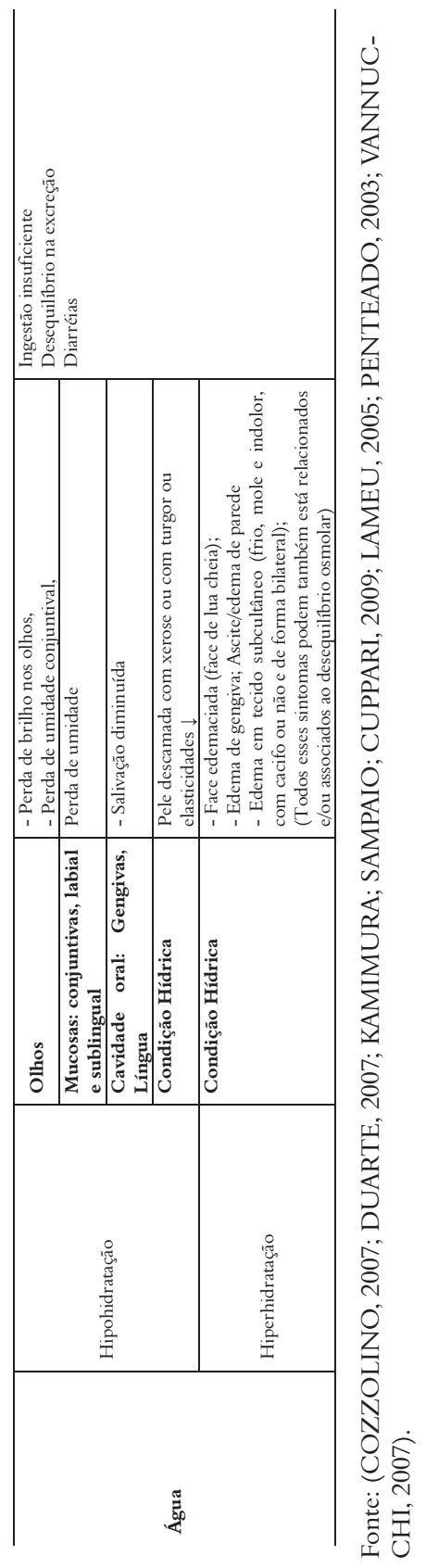

Lílian Sampaio, Maria Silva, Tatiane Oliveira e Venusca Leite 45 


\section{Referências}

BEVILACQUA, Fernando et al. Manual do exame clínico. 11. ed. Rio de Janeiro: Cultura Médica. 1997. 475 p.

COZZOLINO, S. M. F. Deficiências de minerais. Estudos Avançados. São Paulo, v. 60, p. 119-126, 2007.

DUARTE, A. C. Avaliação nutricional: aspectos clínicos e laboratoriais. São Paulo: Atheneu, 2007.

DUARTE, A. C.; CASTELLANI, F. R. Semiologia nutricional. Rio de Janeiro: Axcel Books do Brasil, 2002.

GERUDE M. Terapia Nutricional. São Paulo: Atheneu, 1995.

GIBSON RS. Nutritionnal assessment: a laboratory manual. New York: University Press, 1993. 196 p.

GUIMARÃES R. M.; CUNHA U. G. V. Sinais e sintomas em geriatria. Rio de Janeiro: Ed. Revinter, 1989, 196 p.

KAMIMURA, M. A.; SAMPAIO, L. R.; CUPPARI, L. Avaliação nutricional na prática clínica. In: CUPPARI, L. et al. Nutrição: nas doenças crônicas nãotransmissíveis. Barueri, SP: Manole, 2009.

KATCH, F. J.; MCARDLE W. Nutrição, controle de peso e exercício. 3. ed. Rio de Janeiro: Médica Científica, 1990. 327 p.

LAMEU E. B. Clínica nutricional. Rio de Janeiro: Editora Revinter, 2005.

LÓPEZ, M.; MEDEIROS, JL. Semiologia Médica: as bases do diagnóstico clínico. 4. ed. Rio de Janeiro, RJ: REVINTER, 2001. 1 v.

MAHAN, L. K.; ESCOTT-STUMP, S. (Ed.). Krause alimentos, nutrição e dietoterapia. 10. ed. São Paulo: Rocca, 2002. p. 1157.

MARTINS, C. Avaliação do estado nutricional e diagnóstico. Paraná: Nutroclínica, 2008. $1 \mathrm{v}$.

NEHME, M. N. et al. Contribuição da semiologia para o diagnóstico nutricional de pacientes hospitalizados. Caracas, Archivos Latinoamericanos de Nutrición, Caracas, v. 56, n. 2, p. 153-159, jun. 2006.

OLIVEIRA, D. de.; MARCHINI, J. S. Ciências nutricionais. São Paulo: Sarvier, 1998. p. 19, cap. 2.

ORGANIZAÇÃO MUNDIAL DA SAÚDE (OMS). Ministério da Saúde. Medicion del cambio del estado nutricional. Genebra, 1983. 
ORGANIZAÇÃO PAN - AMERICANA DE SAÚDE (OPAS) /

ORGANIZAÇÃO MUNDIAL DA SAÚDE (OMS). Conocimientos actuales sobre nutrición. Publicación Científica, Washington, n. 565, 731 p. 1997.

PENTEADO, M. V. C. Vitaminas: aspectos nutricionais, bioquímicos, clínicos e analíticos. Barueri, SP: Manole, 2003.

REZENDE, I. F. B. et al. Avaliação muscular subjetiva como parâmetro complementar de diagnóstico nutricional em pacientes no pré-operatório. Revista de Nutrição, Campinas, v. 20, n. 6, p. 613-615, dez. 2007.

SAMPAIO L. R. Avaliação nutricional no envelhecimento. Revista de Nutrição, Campinas, v. 18, n. 4, p. 507-514, out/dez. 2004.

SANTOS, J. B. Ouvir o paciente: a anamnese no diagnóstico clínico. Revista Brasília Médica, São Paulo, v. 36, n. 3, p. 90-95, 1999.

SHILS, M. E. et al. Tratado de nutrição moderna na saúde e na doença. 9. ed. São Paulo: Manole, 2002.

VANNUCCHI, H. Hipovitaminoses: fisiopatologia e tratamento. In: VANNUCCHI, H. et al. Nutrição clínica: nutrição e metabolismo. Rio de Janeiro: Guanabara Koogan, 2007.

WAITZBERG, D. L.; FERRINI, M. T. Avaliação nutricional. In:

WAITZBERG, D. L. Nutrição enteral e parenteral na prática clínica. 2. ed. Rio de Janeiro: Atheneu, 1995. 642 p. 